\title{
As Políticas de Fortalecimento da Gestão Democrática e os Conselhos Municipais de Educação
}

\section{The policies for strengthening the Democratic Administration and the Education Municipal Councils}

\author{
El fortalecimiento de las políticas de la gestión democrática y \\ los Consejos Municipales de Educación
}

\section{Andrea Caldas ${ }^{1}$}

\section{Resumo:}

O artigo analisa a criação e consolidação dos conselhos municipais de educação, à luz do exame da construção histórica da organização da educação nacional e os desafios estabelecidos para o sistema nacional de educação. Reflete ainda sobre as tensões estabelecidas, neste processo, entre a centralização e descentralização, o poder nacional e local, bem como as diferentes concepções de gestão da educação. Para tanto, busca identificar nos textos mais importantes da legislação educacional, do período republicano até os dias atuais, os avanços e limites estabelecidos para a construção da gestão democrática da educação.

Palavras-chave: Politica Educacional; Legislação Educacional; Gestão da Educação; Conselhos de Educação.

\begin{abstract}
:
The article analyzes the creation and consolidation of education municipal councils in the light of the examination of the national education historical organization and the challenges set to a education national system. The article still discuss the tensions established in this process between centralization and decentralization, national and local authorities as well, the different education administration concepts. Therefore, it seeks to identify the most important texts of educational legislation, from the Republican period to the present day, as well the advances and limits for the construction of education democratic management.
\end{abstract}

Keywords: Educational policy; Educational laws; Education Administration; Education councils.

\section{Resumen:}

El artículo analiza la creación y la consolidación de los consejos municipales de educación a la luz del examen de la construcción histórica de la organización nacional de educación y los retos que plantea para el sistema nacional de educação. Reflete ademassobre las tensiones establecidas en este proceso entre la centralización y la descentralización, las autoridades nacionales y locales, así como los diferentes conceptos de gestión de la educación. Por lo tanto, se trata de identificar los textos más importantes de la legislación educativa, desde el período republicano hasta la actualidad, los avances y límites para la construcción de la gestión democrática de la educación.

Palabras-clave: Política Educativa; Legislación de la Educación; Gestión de la Educación; Consejos Educativos. 
A análise sobre os conselhos municipais de educação traz consigo o necessário entrecruzamento dascomplexas dimensões que marcam o debate em torno da elaboração e efetivação das políticas educacionais, em nosso país.

Trata-se tanto do papel dos municípios, como parte do sistema nacional de educação, no que tange a responsabilidades e graus de autonomia, quanto do papel que os conselhos podem ou devem desempenhar na organização dos sistemas e redes.

Muito além de questões técnicas, delineia-se, neste quadro, um campo de disputas em torno de concepções sobre o Estado, a relação com a sociedade e as funções atribuídas à educação institucionalizada.

É fundamental, portanto, que possamos examinar a profundidade dos desafios que se estabelecem na construção e consolidação dos conselhos municipais de educação, ao lado dos sistemas municipais, localizandoos no contexto mais amplo dos debates nacionais no que diz respeito à democratização e gestão da educação.

\section{Educação nacional: centralização e descentralização}

A história da educação brasileira, tal como a do próprio país, revela as contradições do desenvolvimento dependente, em que o projeto de construção nacional foi sendo adiado, improvisado e, no mais das vezes, tornouse um amálgama de ações isoladas e programas destinados a atender conjunturas e interesses específicos.

Assim é que o governo colonial do Brasil, tendo como objetivo primordial a extração da riqueza nacional, assentado sob as bases da exploração do trabalho escravo, tratou de prover a organização da instrução, apenas da elite e com os olhos voltados para fora do país.

Os objetivos da educação jesuítica, de gestão privada e subsidiada pela Coroa portuguesa, que aconteceu de 1549 a 1759,pouco alterados pelas Reformas Pombalinas - a não ser no que diz respeito aos conteúdos - voltavamse, explicitamente, para a preparação dos estudos no exterior, ou em alguns casos, o exercício do sacerdócio.

Com a proclamação da Independência política, em 1822, seria legítimo imaginar que o país reclamasse uma organização da educação nacional, o que se ensaiou fazer com primeira Lei de Educação Nacional, aprovada em 15 de outubro de 1827 que estabelecia:

Art. $1^{\circ} \mathrm{Em}$ todas as cidades, vilas e lugares mais populosos, haverá as escolas de primeiras letras que forem necessárias.

Art. $2^{0}$ Os Presidentes das províncias, em Conselho e com audiência das respectivas Câmaras, enquanto não estiverem em exercício os Conselhos Gerais, marcarão o número e localidades das escolas, podendo extinguir as que existem em lugares pouco populosos e remover os Professores delas para as que se criarem, onde mais aproveitem, dando conta a Assembleia Geral para final resolução.

Art. $3^{0}$ Os presidentes, em Conselho, taxarão interinamente os ordenados dos Professores, regulando-os de $200 \$ 000$ a $500 \$ 000$ anuais, com atenção às circunstâncias da população e carestia dos lugares, e o farão presente a Assembleia Geral para a aprovação.

Art. $4^{\circ}$ As escolas serão do ensino mútuo nas capitais das províncias; e serão também nas cidades, vilas e lugares populosos delas, em que for possível estabelecerem-se.

Art. $5^{\circ}$ Para as escolas do ensino mútuo se aplicarão os edifícios, que couberem com a suficiência nos lugares delas, arranjando-se com os utensílios necessários à custa da Fazenda Pública e os Professores que não tiverem a necessária instrução deste ensino, irão instruirse em curto prazo e à custa dos seus ordenados nas escolas das capitais.

Art. $6^{0}$ Os professores ensinarão a ler, escrever, as quatro operações de aritmética, prática de quebrados, decimais e proporções, as noções mais gerais de geometria prática, a gramática de língua nacional, e os princípios de moral cristã e da doutrina da religião católica e apostólica romana, proporcionados à compreensão dos meninos; preferindo para as leituras a Constituição do Império e a História do Brasil.

A mudança da conjuntura política do país, motivada pelo retorno de D.Pedro I para Portugal e assunção do governo por parte da Regência - além da inexistência de bases materiais que reclamassem a expansão da educação de forma mais ampla - acabou por tornar inócua, a primeira Lei Nacional de Educação.

Isto porque, o Ato Adicional à Constituição, promulgado em 1834, estabeleceu a descentralização administrativa como estratégia de conciliação política e entre outras definições, colocou o ensino primário sob a jurisdição das Províncias, desobrigando o governo central desta atribuição. 
Iniciava-se aqui, o que viria a ser o traço mais persistente das políticas educacionais, ou seja, o movimento pendular entre centralização e descentralização e, na maioria das vezes, combinando a centralização política à mera descentralização administrativa, ou seja, a desconcentração, sem efetiva repartição de poderes.

Importa ressaltar que a tensão entre a centralização ou descentralização dos poderes não se circunscreve apenas aos polos de disputa no interior do Estado, em sentido estrito, ou seja, ao governo central e aos governos locais, mas, também, à disputa da iniciativa privada dos rumos da política estatal bem como, dos fundos públicos.

É este panorama de contradições que irá matizar os caminhos da complexa, e não menos, conflituosa construção do Sistema Nacional de Educação, até os dias atuais. Neste processo, o debate sobre autonomia, democracia, repartição de responsabilidades, financiamento,poder nacional e local demarca alguns dos meandros que precisam ser definidos no terreno da organização nacional da educação.

\section{As bases e organização da educação nacional}

A partir dos anos 1920/30, já sob o regime republicano e com o incremento da industrialização e urbanização do país, será possível observar, com mais nitidez,esforços na direção de se construir um projeto nacional de país e por consequência, a organização da educação nacional.

Se no passado, tais postulados não encontraram organicidade na realidade estrutural brasileira-caracterizada pelo predomínio de atividades econômicas que exigiam pouca ou nenhuma instrução e um cenário político impermeável à participação social - no alvorecer da primeira década do século XX, o Brasil é sacudido por mudanças na base da atividade econômica e nas relações sociais, especialmente, pela abolição do regime de trabalho escravo e a centralidade que a atividade manufatureira passará a ter no cenário produtivo.

Ainda que o escopo deste texto não permita o aprofundamento de tal questão é importante ressaltar que não é ocasional que a ideia de construção de uma organização da educação nacional ganhe força, precisamente, no cenário histórico que combina trabalho livre, urbanização e participação política, ainda que de forma incipiente.

É este conjunto de fatores materiais e culturais que irão reclamar e colocar na ordem do dia o projeto da educação nacional, constantemente adiado. Ou seja, não são "ideias que nasceram de ideias", mas, expressões necessárias do desenvolvimento histórico real, conforme nos explana Gramsci:

É necessário, por conseguinte, distinguir entre ideologias historicamente orgânicas, isto é, que são necessárias a uma determinada estrutura, e ideologias arbitrárias, racionalistas, "desejadas". Na medida em que são historicamente necessárias, as ideologias têm uma validade que é validade "psicológica": elas "organizam" as massas humanas, formam o terreno sobre o qual os homens se movimentam, adquirem consciência de sua posição, lutam etc. Na medida em que são "arbitrárias", elas não criam senão movimentos individuais, polêmicas, etc. (1991 p.62-3)

O Manifesto dos Pioneiros da Escola Nova, fruto dos debates realizados nas Conferências em Educação, organizadas por educadores de vários níveis de ensino e diversos estados, sintetiza a efervescência desta época e apontava o seguinte diagnóstico da educação brasileira:

Se depois de 43 anos de regime republicano, se der um balanço ao estado atual da educação pública, no Brasil se verificará que, dissociadas sempre as reformas econômicas e educacionais, que era indispensável entrelaçar e encadear, dirigindo-as no mesmo sentido, todos os nossos esforços, sem unidade de plano e sem espírito de continuidade, não lograram ainda criar um sistema de organização escolar, à altura das necessidades modernas e das necessidades do país. Tudo fragmentado e desarticulado. A situação atual, criada pela sucessão periódica de reformas parciais e frequentemente arbitrárias, lançadas sem solidez econômica e sem uma visão global do problema, em todos seus aspectos, nos deixa antes a impressão desoladora de construções isoladas, algumas já em ruína, outras abandonadas em seus alicerces, e as melhores, ainda não em termos de serem despojadas de seus andaimes (AZEVED0, 2010, p. 33)

A Constituição de 1934 sofre a influência deste campo progressista e estabelece a necessidade de elaboração das diretrizes da educação nacional e do plano nacional de educação, sob a incumbência do Conselho Nacional de Educação, criado através doDecreto n 19.850, de 11/04/1931. 
Com a ruptura política provocada pelo golpe que instituiu o Estado Novo, uma nova carta constitucional é aprovada com mudanças substanciais acerca do dever do Estado para a educação. O novo entendimento trazido pela Constituição de 1937 é que a educação é dever primeiro da família e, suplementarmente, do Estado que deve atender "aos que faltarem os recursos necessários à educação em instituições particulares"(art. 127).

Tais alterações representam um retrocesso no inicial caminho de construção da organização nacional pública e universal, além de apontar para a concentração das decisões nas mãos do executivo federal - responsável por fixar as bases e traçar as diretrizes a "que deve obedecer a formação física, intelectual e moral da infância e da juventude" (art.15, inciso IX). Não há menções ao Conselho Nacional da Educação, tampouco ao Plano Nacional que havia sido formulado recentemente.

O novo contexto econômico, contudo, exigia que houvesse uma relativa expansão da educação, ao menos nos seus níveis iniciais, para responder às demandas do mercado de trabalho e isto foi feito através dos DecretosLeis baixados entre 1942 e 1946, também conhecidos por Reforma Capanema. Ou seja, a necessidade de organização da educação inicial acabou por ser atendida, porém, de forma verticalizada e centralizadora.

Com a reabertura política, em 1946, o debate sobre as diretrizes e bases da educação nacional volta à cena, e inicia-se o processo de elaboração da primeira Lei de Diretrizes e Bases da Educação Nacional (LDB). A elaboração, que perdurou treze longos anos de intensas discussões, no Congresso, expôs novamente o embate entre as tendências centralizadoras e descentralizadoras. Desta feita, porém, com participação decisiva dos representantes da iniciativa privada que se opunham, não somente, à concentração das decisões nas mãos do governo federal, mas, defendiam a menor regulamentação possível da educação sob a postulação da "liberdade do ensino", contraposta ao dever do Estado e o direito à educação. ${ }^{2}$

Como resultado das conciliações e negociações, a Lei 4024/61 acabou por consolidar um texto intermediário entre os defensores da livre iniciativa e desregulamentação e os que defendiam a estruturação da educação nacional, coordenada pelo Estado.

Um dos exemplos desta "solução de compromisso", como explana Saviani (1997), é a manutenção do capítulo "da liberdade do ensino" proposto pelo deputado Carlos Lacerda, ao lado do título "dos sistemas de ensino", que constava do projeto original. "O título da liberdade do ensino era uma reivindicação da iniciativa privada, ao passo que o título referente aos sistemas de ensino implicava a precedência da iniciativa do poder público" (p.19).

Contudo, mais uma vez o longo processo de discussão e maturação política é abortado por uma nova ruptura institucional, com o golpe militar em 1964 que, apesar de manter parte do texto da LDB, aprovado em 61, no que se refere aos princípios e objetivos, reformulou a estrutura do ensino básico e superior, através das Leis 5.540/68 e 5.692/71.

A ideia da construção de um consenso nacional em torno de um Plano Nacional de Educação e da consolidação de espaços colegiados de tomada de decisão foi substituída por projetos estratégicos setoriais com forte acento tecnicista, cujas decisões eram centralizadas no MEC e subordinadas ao "Plano Geral do Governo" (art.53, Lei 5692/71).

Ao lado da concentração de poder, são estimuladas estratégias de descentralização administrativa e "flexibilidade pedagógica", como por exemplo, a instituição da parte diversificada dos currículos, a ser definida pelos Conselhos Estaduais e até o estímulo à criação de conselhos municipais de educação. Tratava-se, todavia, da conhecida estratégia de desconcentração de tarefas, enquanto se mantém intocado o centro das decisões.

Com os ventos da redemocratização do país, nos anos 80, a comunidade educacionalvolta a pautar o tema do sistema nacional de educação e sua democratização, tanto do ponto de vista da universalização da oferta e permanência, quanto da gestão.

2 Dermeval Saviani (1997) no livro A Nova Lei da Educação:Trajetória, Limites e Perspectivas examina, em detalhe, os vários debates que ocorreram durante a tramitação da Lei 4024/61, analisando as posições defendidas pelos parlamentares e suas articulações com os grupos e concepções educacionais em disputa (p. 11-21) 
As Conferências Brasileiras de Educação (CBE) são organizadas por iniciativa de associações nacionais de professores, principalmente, a Confederação Nacional de Trabalhadores em Educação (CNTE), a Associação Nacional de Pós-Graduação e Pesquisa em Educação (ANPED) e Associação Nacional Docente (ANDE).

Acontecem cinco sessões que antecedem a formulação de propostas para a Constituinte e para a Lei de Diretrizes e Bases da Educação: 1. ${ }^{a}$ CBE/1980 (abril), em São Paulo com 1,4 mil participantes; 2. ${ }^{a}$ CBE/1982 (junho), em Belo Horizonte com 2 mil participantes; 3. ${ }^{a} \mathrm{CBE} / 1984$ (outubro) com 5 mil participantes; $4 .{ }^{a} \mathrm{CBE} / 1986$ (setembro), em Goiânia com 6 mil participantes e 5. ${ }^{a} \mathrm{CBE} / 1988$ (agosto), em Brasília com 6 mil participantes (CUNHA, 1995, p. 94).

Das quatro primeiras conferências resulta a emenda popular apresentada ao capítulo da educação na constituinte e da última, a proposta de projeto de Lei de Diretrizes e Bases da Educação Nacional (SOUZA et alii, 2005).

Esta intensa organização contribui para que a nova Constituição de 1988 e o projeto de LDB recuperassem muitos dos princípios legados pelos Pioneiros da Educação Nova, ampliados pelas experiências dos movimentos sociais, desde os anos 1960.

A nova Carta Constitucional afirma o dever do Estado, a gratuidade do ensino nos estabelecimentos oficiais, o direito público subjetivo, em matéria de educação e estabelece a necessidade de formulação de plano nacional de educação, com duração plurianual, "visando à articulação e ao desenvolvimento do ensino em seus diversos níveis e à integração das ações do Poder Público" (art.214, redação original).

Na sequencia, o processo de elaboração da nova LDB, será palco de nova disputa entre os movimentos sociais em defesa da escola pública e representantes da iniciativa privada, especialmente nas questões que afetam a regulamentação, o financiamento e o papel do Estado.

Entre as várias polêmicas, a ideia da constituição de um sistema nacional de educação que articule os vários sistemas e redes, a partir de um conjunto de normas e diretrizes comuns, apresentado pelas entidades educacionais, encontrou forte resistência.

O texto final, promulgado em 1996, consignará os acordos possíveis entre as forças políticas atuantes na área de educação, no governo e no parlamento e aponta para princípios da organização nacional, sem referência ao sistema nacional de educação, que foi objeto de contestações, inclusive no campo jurídico, "pois se argumentava que na Constituição não aparecia a expressão sistema nacional de educação, mas apenas, sistemas de ensino" (SAVIANI, 1997, p.207)

O tema será retomado nas discussões do PlanoNacional de Educação e apresentado a partir da proposta organizada pelas entidades e movimentos sociais da educação, no II CONED ${ }^{3}$. Na redação aprovada pelo Congresso e sancionada pelo presidente Fernando Henrique Cardoso, em 2001, novamente, a menção à referência ao sistema nacional é substituída pela ideia de regime de colaboração entre sistemas de ensino. Entretanto, o mesmo PNE institui o Sistema Nacional de Avaliação.

Desta forma, as políticas educacionais permanecem marcadas pela centralização das decisões - e avaliação - no campo do executivo federal e a repartição das responsabilidades entre os demais entes federados, sem necessária contrapartida de financiamento e estrutura.

A crítica a este modelo, combinada ao diagnóstico de manutenção das desigualdades e exclusão no campo educacional, não obstante as metas legais e constitucionais, irão demarcar a mobilização em torno do novo Plano Nacional de Educação (PNE).

Neste cenário, a Emenda Constitucional n 59, aprovada em 2009, representou um importante avanço ao incluir, no texto Constitucional,a necessidade de que o Plano Nacional de Educação defina a articulação do sistema nacional de educação.

3 II Congresso Nacional de Educação, promovido, em Belo Horizonte, em 1997, pelo Fórum Nacional em Defesa da Escola Pública. 
A complexa construção da organização nacional de educação - matizada pelas tensões entre poder local e central, interesse público e privado, centralização e descentralização - ingressa, desta feita, em nova etapa, de vez que, ao menos, do ponto de vista legal, os obstáculos para a constituição do sistema nacional de educação foram suprimidos, o que não significa, contudo, que as dificuldades tenham sido vencidas.

Tanto assim que oSistema Nacional de Educação e o regime de colaboração entre a União, Estados e Municípios foram os temas centrais das duas Conferências Nacionais de Educação ${ }^{4}$, convocadas pelo governo e organizadas conjuntamente com a sociedade civil, em 2010 e 2014.

O novo Plano Nacional de Educação, aprovado pela Lei 13.005 de 2014, define o prazo de dois anos para que o poder público institua, através de lei específica, "o Sistema Nacional de Educação, responsável pela articulação entre os sistemas de ensino, em regime de colaboração, para efetivação das diretrizes, metas e estratégias do Plano Nacional de Educação" (art.13).

Ainda assim, a solução desta equação está longe de guardar consensos e acordos de fácil resolução.

\section{A educação no plano municipal e o sistema nacional de educação}

A Lei de Diretrizes e Bases da Educação Nacional, de 1996, acompanhando a tendência expressa na Carta Constitucional de 1988, amplia o espectro de ação e atribuições dos municípios, cabendo-Ihe, inclusive, escolher a forma de organização da educação municipal, se através de um sistema próprio ou integrando-se ao sistema estadual de educação:

Art. $8^{\circ}$ A União, os Estados, o Distrito Federal e os Municípios organizarão, em regime de colaboração, os respectivos sistemas de ensino.

(...)

Art. 11. Os Municípios incumbir-se-ão de:

I - organizar, manter e desenvolver os órgãos e instituições oficiais dos seus sistemas de ensino, integrando-os às políticas e planos educacionais da União e dos Estados;

II - exercer ação redistributiva em relação às suas escolas;

III - baixar normas complementares para o seu sistema de ensino;

IV - autorizar, credenciar e supervisionar os estabelecimentos do seu sistema de ensino;

$\checkmark$ - oferecer a educação infantil em creches e pré-escolas, e com prioridade, o ensino fundamental, permitida a atuação em outros níveis de ensino somente quando estiverem atendidas plenamente as necessidades de sua área de competência e com recursos acima dos percentuais mínimos vinculados pela Constituição Federal à manutenção e desenvolvimento do ensino.

$\mathrm{VI}$ - assumir o transporte escolar dos alunos da rede municipal.

Parágrafo único. Os Municípios poderão optar, ainda, por se integrar ao sistema estadual de ensino ou compor com ele um sistema único de educação básica (LEl 9394/96).

Além de definir as atribuições específicas do município, o texto legal aponta para a necessidade do regime de colaboração, no interesse da educação nacional.

Pode-se indicar que cabe ao município colaborar com a União: na elaboração do Plano Nacional de Educação; recebendo assistência técnica e financeira para 0 desenvolvimento de seus sistemas de ensino e para 0 atendimento prioritário da escolaridade obrigatória; no estabelecimento de competências e diretrizes para a educação infantil, ensino fundamental e ensino médio; na construção de um processo nacional de avaliação do rendimento; oferecendo informações e dados necessários sobre os estabelecimentos de ensino e órgão educacionais de seu sistema (...).

4 A realização das Conferências Nacionais de Educação (CONAE), a partir de 2010, demarca um importante momento na institucionalização dos canais de participação no debate das políticas educacionais. Convocadas pelo governo, atendendo a uma antiga reivindicação da comunidade educacional organizada, as conferências foram organizadas de forma conjunta com representantes das secretarias do Ministério da Educação, da Câmara e do Senado, do Conselho Nacional de Educação, das entidades dos dirigentes estaduais, municipais e federais da educação, dos trabalhadores em educação, estudantes e demais entidades que atuam direta ou indiretamente na educação. (http://conae.mec.gov.br/) 
Já com o estado, a LDB estabelece que o município deva definir as formas de colaboração para a oferta do ensino fundamental, devendo assegurar a distribuição proporcional das responsabilidades, de acordo com a população a ser atendida e os recursos financeiros disponíveis em cada uma dessas esferas do poder público. Define, ainda, que ele necessita coordenar suas ações com as de seu estado assegurando, por exemplo, transporte escolar para seus estudantes (GRACIND0, 2010, p.231-32).

Ainda que a legislação aponte, portanto, para a organização mais autônoma dos municípios, a regulamentação do regime de colaboração ainda não foi realizada tampouco, a organização do Sistema Nacional de Educação. Desta feita, o risco de que autonomia torne-se letra morta ou acentue a desigualdade e fragmentação da educação é evidente.

Neste árduo processo de negociação e pactuação entre os entes federados, questões como repartição do poder e capacidade de financiamento emergem como cruciais, especialmente, no que se refere aos 5.570 municípios, em condições absolutamente assimétricas.

Cerca de 70\% dos 5570 municípios podem ser considerados pobres e muito pobres, por serem pequenos (não atingem 20000 habitantes) e não conseguirem arrecadar recursos próprios, proporcionais às suas necessidades de implantação dos direitos sociais básicos, e, portanto, dependem da redistribuição de recursos da União. Por outro lado, 220 municípios, somente, agregam 75\% da população brasileira (municípios com mais de 100 mil habitantes) e, por consequência, são responsáveis pelas políticas sociais para esse total de pessoas (ARELARO, 2015, p.32-3).

É preciso considerar que a própria questão dos níveis de autonomia municipal e a organização dos sistemas não é um ponto pacificado, mesmo entre a comunidade educacional.Saviani, por exemplo, em sua análise dos projetos de LDB discorda da instituição dos sistemas municipais de educação, dado que a Constituição estabelece privativamente à União a tarefa de legislar sobre diretrizes e bases da educação nacional e aos estados e Distrito Federal, a função de "legislar concorrentemente" sobre educação, cultura, ensino e desporto. Segundo o autor, "é competência comum da União, dos estados, do Distrito Federal e dos municípios proporcionar os meios de acesso à cultura, à educação e à ciência" (SAVIANI, 1997, p.62).

Desta interpretação decorre que "não tendo autonomia para baixar normas próprias sobre educação ou ensino, os municípios estão constitucionalmente impedidos de instituir sistemas próprios, isto é, municipais, de educação ou de ensino" (SAVIANI, 1997, p.63).

Ainda assim, "o texto constitucional deixa margem, no art.211, para que se possa falar em sistemas de ensino dos Municípios", o que, segundo o autor, confere ao termo uma ambiguidade por uso analógico, ou seja, trata-se de organização de redes de escolas e não de sistemas de educação (SAVIANI, 1997, p.63).

O projeto Jorge Hage, aprovado na comissão de educação da Câmara Federal, indicou a organização de sistemas de ensino da União, Estados e Municípios (art.11), prevendo, inclusive, a existência de órgãos coletivos normativos, para efeitos de planejamento e administração democrática, de forma colegiada e representativa (SAVIANI, 1997, p.74-76).

Já, o texto final da LDB manteve a expressão sistemas de ensino municipais, mas, não faz referência a órgãos coletivos normativos, ou seja, aos conselhos municipais de educação.

\section{A gestão educacional e os conselhos de educação}

Se o debate em torno das diferentes responsabilidades e atribuição entre os entes federados reveste-se da tensão advinda da disputa de poderes e do reconhecimento da diversidade e desigualdade, que marca a organização da educação nacional, a criação e consolidação deorganismos colegiados defronta-se com outra série de obstáculos, de natureza política e normativa.

A necessidade da criação de um órgão ligado ao Ministério da Educação, para fins de normatização, aparece no contexto da Reforma Rivadávia, em 1911, que pretendia regulamentar a oferta de ensino superior no país e cria através do Decreto 8659/1911, o Conselho Superior de Ensino. 
Contudo, é a Carta Magna de 1934, inspirada pelos debates dos Congressos de Educação e o Manifesto dos Pioneiros da Educação Nova, que irá constitucionalizar o Conselho Nacional de Educação, estabelecendo além das funções normativas e de assessoria, a tarefa de elaborar o Plano Nacional de Educação bem como, estendendo para os Estados, a necessidade de criação de seus Conselhos de Educação:

Art. 152 - Compete precipuamente ao Conselho Nacional de Educação, organizado na forma da lei, elaborar o plano nacional de educação para ser aprovado pelo Poder Legislativo e sugerir ao Governo as medidas que julgar necessárias para a melhor solução dos problemas educativos bem como a distribuição adequada dos fundos especiais.

Parágrafo único - Os Estados e o Distrito Federal, na forma das leis respectivas e para o exercício da sua competência na matéria, estabelecerão Conselhos de Educação com funções similares às do Conselho Nacional de Educação e departamentos autônomos de administração do ensino (BRASIL, 1934).

Neste sentido, a criação dos Conselhos, neste período, associa-se ao sentido de planejamento e articulação das ações institucionais, fortemente, presente nas preocupações da época, assim traduzidas pelos Pioneiros da Educação Nova:

Em lugar dessas reformas parciais, que se sucederam,na sua quase totalidade, na estreiteza crônica de tentativasempíricas, o nosso programa concretiza uma nova política educacional,que nos preparará, por etapas, a grande reforma, em quepalpitará, com o ritmo acelerado dos organismos novos, o músculocentral da estrutura política e social da nação.Em cada uma das reformas anteriores, em que impressionavivamente a falta de uma visão global do problema educativo, aforça inspiradora ou a energia estimulante mudou apenas de forma,dando soluções diferentes aos problemas particulares. (...)É preciso, porém, atacar essa obra, por um plano integral, para que ela não se arrisque um dia a ficar no estado fragmentário, semelhante a essas muralhas pelágicas, inacabadas, cujos blocos enormes, esparsos ao longe sobre 0 solo, testemunham gigantes que os levantaram, e que a mortesurpreendeu antes do coroamento de seus esforços (AZEVEDO, 2010, p.39)

Esta função atribuída aos Conselhos se manterá praticamente inalterada, nas normatizações subsequentes desses órgãos. Contudo, a questão da composição dos mesmos pautará, de forma bastante contundente, os debates em torno da Lei de Diretrizes e Bases da Educação Nacional, após a Constituição de 1988.

Destarte, se o planejamento educacional demarca a tônica das preocupações dos anos 1930 aos $1970^{5}$, nas suas diversas concepções e encaminhamentos institucionais, o tema da participação da sociedade civil na tomada de decisões sobre a política educacional, emergirá no contexto de redemocratização do país como agenda proeminente nos embates entre governos e organizações sociais.

Neste caminho, o projeto de LDB, elaborado pelas entidades participantes da V Conferência Brasileira da Educação (CBE), estabelecia o Conselho Nacional de Educação como organismo responsável pela articulação do sistema nacional de educação assumindo, portanto, um papel de protagonismo na elaboração e gestão da política educacional do país.

A proposta de composição incluía uma significativa participação da sociedade civil organizada, além das representações dos governos. Tal indicação foi acolhida pelo deputado Octávio Elísio, autor do projeto de lei e mantida no texto aprovado na Comissão de Educação da Câmara, a partir de relatoria do deputado Jorge Hage.

Contudo, pretextando a inconstitucionalidade da proposta - a partir da interpretação de que o legislativo não poderia tratar de órgãos vinculados à administração direta do Executivo - setores contrários a esta proeminência de um órgão colegiado na gestão da política educacional, lograram retirar, do texto final da LDB, a menção à composição do Conselho, fazendo prevalecer suas funções consultivas e normativas, porém, vinculadas ao MEC (SAVIANI, 1997).

Os Conselhos Estaduais e Municipais, ao contrário de legislações anteriores, não são citados na nova LDB, ainda que a lei faça referência ao estabelecimento de normas próprias de cada sistema de ensino, o que faz supor a existência de órgãos normativos.

5 Bordignon (2013), em importante estudo sobre o Planejamento Educacional no Brasil, analisa as diversas fases e concepções que atravessam as ações institucionais de planejamento, dos anos $\mathbf{3 0}$ aos dias atuais. 
Dessa forma, a própria definição sobre função e composição dos conselhos caberá a cada sistema. No âmbito federal, o Conselho Nacional de Educação inclui a representação da sociedade civil, contudo, os indicados são escolhidos e nomeados pelo Ministro, configurando uma espécie de democracia consentida.

No âmbito dos estados, há diversas formas de composição e de definição de funções, prevalecendo a ideia dos conselhos como órgãos colegiados, aos quais compete estabelecer a relação entre a sociedade e o governo (CURY, 2000).

No caso dos municípios, embora, muitos dos seus conselhos tenham sido criados, ainda sob a égide da Lei 5692/71, há uma miríade de situações diversas no que diz respeito à autonomia do próprio município em relação ao sistema estadual, o que por sua vez, condiciona as próprias atribuições dos conselhos.

A constituição dos sistemas municipais de ensino foi tratada na LDB sendo firmada a possibilidade, ainda, de optar entre compor com o Estado um sistema único, ou manter-se integrado ao sistema estadual. Nesse contexto, diferentes orientações têm sido formuladas pelos governos estaduais, a partir das secretarias de educação ou dos conselhos estaduais de educação, no que diz respeito ao processo de municipalização do ensino, constituição dos sistemas municipais de ensino e criação dos conselhos municipais de educação (TEIXEIRA, 2004, p. 700).

Tais diferenças são evidenciadas nos dados levantados pelo IBGE, em 2011, que informa haver, no Brasil, 4.718 conselhos municipais, porém, apenas, 2.048 municípios com sistemas de ensino. No Paraná, segundo este levantamento, há 267 conselhos municipais e 22 sistemas municipais de ensino.

Este complexo quadro delineado até aqui, em um processo político e social, marcado por avanços, recuos, novas possibilidades e renovados desafios demarca parte fundamental da pauta da área de gestão educacional.

Temos como tarefa históricaa definição e pactuação dos contornos que pretendemos para o sistema nacional de educação, sem desconsiderar os diferentes graus de autonomia dos entes federados e também, a sua capacidade de financiamento e execução da política nacional.

No campo dos modelos e concepções de gestão, a implantação de mecanismos colegiados e representativos dos diferentes segmentos do campo educacional ainda esbarra na tradição do que denominei, em outro texto, da "democracia monárquica"(NUNES, 1999), ou seja, a concentração de poderes de decisão nas mãos de quem foi eleito para representar uma coletividade, mas que dela se distancia ou não mantém uma relação de organicidade.

Sendo assim, ainda que na democracia representativa os governantes sejam eleitos, entende-se que a ampliação e efetividade da democracia exige a criação de mecanismos de acompanhamento, consulta e controle do poder de quem dirige.

No caso das políticas educacionais, a nossa defesa é de, que tal como sonhavam os pioneiros da Educação Nova, nos anos 1930, possamos construir coletivamente os rumos e instrumentos de elaboração, implantação e avaliação do projeto educacional.

Nesta trilha, os conselhos de educação como espaços de participação organizada e compartilhamento de decisões do poder público e da comunidade educacional, aliados a outros mecanismos de consulta como os fóruns e as conferências podem amalgamar propostas e soluções para a democratização da educação.

Mas, para que não se convertam em meros órgãos de decisão cartorial é preciso que possuam autonomia política e de gestão financeira, e isto precisa ser consignado na legislação, como forma de minimizar as flutuações de poder e a descontinuidade de processos.

Muitos passos já foram dados nesta direção, outros tantos ainda serão necessários, mas, tenho certeza de que caminhamos ao lado de muitos e muitas que desejam consolidar a tão almejada democratização da educação brasileira. 


\section{Referências:}

ABICALIL, C. Construindo o Sistema Nacional Articulado de Educação. In: CONAE(org.) Conferência Nacional de Educação 2010. Reflexões sobre a construção do Sistema Nacional Articulado de Educação e o Plano Nacional de Educação. Brasília: INEP, 2009.

ANDE, ANPED, CEDEC, CEDES. I Conferência Brasileira de Educação: Anais. São Paulo: Cortez, 1981.

ARELARO,L. É possível implantar, em curto prazo, um sistema nacional de educação no Brasil? In: CALDAS, A. (org.). O Plano Nacional de Educação e o Sistema Nacional de Educação.Livro1. CONAE PARANÁ: Reflexões e provocações. Curitiba, Appris, 2015.

AZEVEDO, F. Manifesto dos pioneiros da Educação Nova (1932). Coleção Educadores. MEC, Fundação Joaquim Nabuco: Editora Massargana, 2010.

BRASIL. Constituição [de 1934] da República dos Estados Unidos do Brasil.Diário Oficialda União [da] República Federativa do Brasil. Rio de Janeiro, 16 jul. 1934.

BRASIL. Constituição [de 1988] da República Federativa do Brasil.Diário Oficialda União [da] República Federativa do Brasil, Brasília, 5 out. 1988.

BRASIL. Emenda Constitucional n 59, de 11 de novembro de 2009.Diário Oficialda União [da] República Federativa do Brasil, Brasília, 12 nov. 2009.

BRASIL. Lei n 10.172, de 09 de janeiro de 2001. Aprova o Plano Nacional de Educação (PNE). Diário Oficialda União [da] República Federativa do Brasil, Brasília, 10 jan. 2001.

BRASIL. Lei no 9.394, de 20 de dezembro de 1996. Estabelece asDiretrizes e Bases da Educação Nacional. Diário Oficialda União [da] República Federativa do Brasil, Brasília, 23 dez. 1996a.

BRASIL. Lei n 13.005, de 25 de junho de 2014. Aprova o Plano Nacional de Educação (PNE) e dá outras providências. Diário Oficialda União [da] República Federativa do Brasil, Brasília, 26 jun. 2014.

BRASIL. Ministério da Educação. Secretaria Executiva. Conferência Nacional de Educação 2010 - Construindo o sistema nacional articulado de educação: o plano nacional de educação, diretrizes e estratégias de ação. Documento Final. Brasília: MEC, 2010.

BOBBIO, N. Estado, governo e sociedade. Rio de Janeiro: Paz e Terra, 1995.

BORDIGNON, G. et alii. O planejamento educacional no Brasil. Fórum Nacional de Educação, junho/2011. Disponível em: <fne.mec.gov.br/pdf/planejamento_educacional_brasil.pdf> Acesso em: 25/03/2013.

CALDAS, A. Do Fórum Paranaense em Defesa da Escola Pública ao Fórum Estadual de Educação do Paraná: Continuidades e Rupturas na Relação Estado e Sociedade Civil. In: CALDAS, A. (org.). O Plano Nacional de Educação e o Sistema Nacional de Educação. Livro 1. CONAE PARANÁ: Reflexões e provocações. Curitiba, Appris, 2015.

COUTINHO, C. A democracia como valor universal e outros ensaios. Rio de Janeiro: Salamandra, 1984.

CUNHA, L. Educação, Estado e Democracia no Brasil. São Paulo: Cortez Niterói: UFF, 1995.

CURY, C. R. J. Os Conselhos de educação e a gestão dos sistemas. In: FERREIRA, N. S. C.; AGUIAR, M. A. S. (org.) Gestão da educação. São Paulo: Cortez, 2000. p.43-60.

Conselhos de educação: fundamentos e funções. RBPAE,v.22- n.1, jan/jun, 2006.

DOURADO, L.F. Plano Nacional de Educação, Conferência Nacional de Educação e a Construção do Sistema Nacional de Educação: Dilemas e Proposições. In: CALDAS, A. (org.). O Plano Nacional de Educação e o Sistema Nacional de Educação. Livro 1. CONAE PARANÁ: Reflexões e provocações. Curitiba, Appris, 2015.

FÓRUM Nacional em Defesa da Escola Pública. Plano Nacional de Educação: proposta da sociedade brasileira. [Consolidado na plenária de encerramento do II CONED, II Congresso Nacional de Educação. Belo Horizonte], nov. 1997.

GRACINDO, R. Sistemas municipais de ensino: limites e possibilidades. In: BRZEZINSKI, I. (org). LDB dez anos depois: reinterpretação sob diversos olhares.São Paulo, Cortez, 2010. 
GRAMSCI, A. Concepção Dialética da História.9a. Edição. Rio de Janeiro, Civilização Brasileira, 1991. IANNI,O. A ideia de Brasil moderno. São Paulo: Brasiliense, 1992.

NUNES, A. C. Gestão democrática ou colegiada: uma (não) tão simples questão de semântica". Caderno Pedagógico 2. Curitiba: APP-SINDICATO, 1999.

PERONI, V. \& FLORES, M.L. Sistema nacional, plano nacional e gestão democrática da educação no Brasil: articulações e tensões. Educação, Porto Alegre, v. 37, n. 2, p. 180-189, maio-ago. 2014

SAVIANI,D. A Nova Lei da Educação. Cortez, São Paulo, 1997.

SOUZA, A.et alli. Gestão Democrática da Escola Pública. Coleção Gestão e Avaliação da Escola Pública. UFPR/MEC, Curitiba. Editora UFPR, 2005.

TEIXEIRA, L. Conselhos municipais de educação: autonomia e democratização do ensino. Cadernos de Pesquisa, v. 34, n. 123, p. 691-708, set./dez. 2004.

Recebido em Junho de 2015 | Aprovado emJaneiro de 2016 